\title{
Médico como arquiteto da escolha: paternalismo e respeito à autonomia
}

\author{
Andrei Ferreira de Araújo Lima ${ }^{1}$, Fernando Inglez de Souza Machado ${ }^{1}$
}

1. Pontifícia Universidade Católica do Rio Grande do Sul, Porto Alegre/RS, Brasil.

\begin{abstract}
Resumo
A relação médico-paciente difere significativamente das demais interações sociais. Não por acaso, cresce expressivamente o número de estudos voltados exclusivamente à referida área. O fortalecimento da concepção de autonomia passou também a abranger a figura do paciente, com notória ampliação de sua esfera de participação e de influência na tomada de decisão em tratamentos e em procedimentos clínicos, mitigando aquela concepção exacerbadamente paternalista que recaía sobre a figura do profissional médico. Porém, daí insurge grave problemática: quais são os limites dessa autonomia? Acredita-se que a solução se encontra na ideia do paternalismo libertário, tese de Richard Thaler e Cass Sunstein, em que o médico atua como arquiteto da escolha do paciente. A partir do método hipotético-dedutivo, o objetivo do presente ensaio é verificar a possibilidade de adequar o método do paternalismo libertário à prática médica, mormente em relação aos hard cases, estabelecendo o alcance e os limites da autonomia do paciente.
\end{abstract}

Palavras-chave: Relações médico-paciente. Autonomia pessoal. Paternalismo. Recusa do paciente ao tratamento.

\section{Resumen}

\section{El médico como arquitecto de elección: paternalismo y respeto por la autonomia}

La relación médico-paciente difiere significativamente de otras interacciones sociales. No es coincidencia que haya un aumento expresivo de estudios centrados exclusivamente en esta área. El fortalecimiento del concepto de autonomía ha abarcado también la figura del paciente, con una notable ampliación de su esfera de participación y influencia en las decisiones sobre tratamientos y procedimientos clínicos, mitigando la concepción extremadamente paternalista que recae en la figura del profesional médico. Sin embargo, esto plantea un problema grave: ¿dónde están los límites de esta autonomía? El artículo argumenta que la solución radica en la idea de paternalismo libertario propuesta por Richard Thaler y Cass Sunstein, según la cual el médico actuaría como el arquitecto de elección del paciente. Con base en el método hipotético-deductivo, el objetivo de este estudio fue verificar la posibilidad de adaptar la metodología del paternalismo libertario a la práctica médica, especialmente con relación a los casos difíciles (hard cases), para establecer el alcance y los límites de la autonomía del paciente.

Palabras clave: Relaciones médico-paciente. Autonomía personal. Paternalismo. Negativa del paciente al tratamiento.

\begin{abstract}
Physicians as choice architects: paternalism and respect for autonomy

The doctor-patient relationship differs significantly from other social interactions, and in the last years studies on this subject have grown significantly. The concept of autonomy now also encompasses patients, with notable expansion of their sphere of participation and influence in decision-making in treatments and clinical procedures, mitigating that overly paternalistic role of the physician. But this change poses a serious question: what are the limits of this autonomy? This article believes in the solution of libertarian paternalism, an idea proposed by Richard Thaler and Cass Sunstein, in which the doctor acts as a choice architect for the patient. Based on the hypothetico-deductive method, this study verifies the possibility of adapting libertarian paternalism to current medical practices, mainly in hard cases, establishing the scope and limits of patient autonomy.
\end{abstract}

Keywords: Physician-patient relations. Personal autonomy. Paternalism. Treatment refusal. 
Pode o paciente escolher tratamento que, dentro do espectro apresentado, seja o de menor efetividade de acordo com o atual estado da arte? Pode ele recusar tratamento, mesmo que o resultado dessa negativa seja a morte? Como pode ficar a cargo de pessoa sem os necessários conhecimentos científicos decisão que depende de tais saberes?

As respostas que este artigo visa oferecer não se baseiam na concepção de autonomia do paciente enquanto valor absoluto, tampouco buscam reestabelecer relação excessivamente paternalista, na qual o profissional médico é detentor exclusivo do poder de decisão. Propõe-se solucionar o impasse a partir da análise do conceito de "arquitetura da escolha", apresentado pelo economista Richard $\mathrm{H}$. Thaler e pelo filósofo Cass R. Sunstein ${ }^{1}$ na obra Nudge: improving decisions about health, wealth, and happiness. Segundo os autores, se você é médico e deve descrever as alternativas de tratamento disponíveis a um paciente, você é o arquiteto da escolha ${ }^{2}$.

Trata-se, em suma, da concepção de um "paternalismo libertário", que se fundamenta em manter as liberdades de escolha, porém otimizando-as, de modo que as pessoas sejam instigadas, jamais coagidas, a tomar as melhores decisões de acordo com o conhecimento científico que permeia o assunto em questão. Na relação entre médico e paciente, por exemplo, cabe à ciência médica desempenhar esse papel.

Certo é que o conhecimento técnico, em se tratando de relações humanas, não poderá prevalecer em toda e qualquer circunstância. Inúmeros outros aspectos de cunho pessoal, social e até mesmo legal devem ser considerados. Posto isto, este artigo busca apresentar o conceito de "arquitetura da escolha" inserido na prática médica, seus reflexos e limites jurídicos, analisando-o em conjunto com o Código de Ética Médica (CEM) ${ }^{3}$ e com as Resoluções do Conselho Federal de Medicina (CFM) $1.805 / 2006^{4}, 1.995 / 2012^{5}$ e $2.232 / 2019^{6}$.

Antes, no entanto, é importante asseverar que não são objeto de análise deste trabalho casos que envolvam pacientes civilmente incapazes ou pessoas com doenças que restringem a capacidade cognitiva. Esses casos demandam intervenção dos responsáveis legais e envolvem toda uma sistemática diversa de atuação que foge, a priori, da concepção de paternalismo libertário, visto que a decisão é necessariamente tomada por um terceiro. Nesse sentido, este ensaio se presta apenas às relações em que o paciente é civilmente capaz e apto a exercer sua autonomia de forma livre e esclarecida.

Destarte, valendo-se do método hipotético-dedutivo, propõe-se aplicar a concepção de paternalismo libertário na área médica, trabalhando os principais pontos da discussão a partir de hard cases. Para tanto, utiliza-se a jurisprudência nacional e internacional, bem como a análise da doutrina em matéria de bioética e da legislação pátria aplicável.

\section{Paternalismo médico versus autonomia do paciente}

A autonomia do paciente é um dos principais direitos responsáveis por romper a barreira do que ficou conhecido como "paternalismo médico". Kraut ${ }^{7}$ esclarece, contudo, que o termo "paternalismo" não contém, a priori, conotação negativa. "Paternalismo" corresponde a comportamento de cuidado, no melhor sentido da relação entre pai e filho, de modo que aquele sempre busca o melhor para este.

Porém, quando o paciente é civilmente capaz, em pleno gozo de sua capacidade cognitiva e responsável por seus próprios atos, inexiste qualquer fundamento para se sustentar suficientemente que sua relação com o médico deva se adequar ao paternalismo clássico, que exclui o paciente do processo decisório. Em muito dos casos, essa dinâmica pouco salutar acaba por aviltar direitos fundamentais ${ }^{8}$.

A esse respeito, é importante salientar que o próprio conceito de saúde, objeto da atuação médica, se transformou ao longo da história, não mais se limitando à ausência de doenças. Atualmente, como apontam Sarlet e Molinaro?, a concepção de saúde é trabalhada sob perspectiva sistemática, aproximando-se da ideia de bem-estar físico, mental e social, conforme preconiza o preâmbulo da Constituição da Organização Mundial da Saúde ${ }^{10}$, de 1946 . Ou seja, o médico não deve se atentar apenas ao bem-estar físico do paciente, mas às consequências psicológicas e até sociais de determinada intervenção.

Por outro lado, não se pode ignorar a maior aptidão do profissional médico para tomar a decisão mais eficaz quanto a determinado tratamento. 
Nesse sentido, é imperioso investigar quão autônomas são, de fato, as decisões pessoais. Seria falacioso afirmar que as pessoas sempre se determinam de modo autônomo? Segundo Thaler e Sunstein ${ }^{1}$, a resposta é afirmativa, pois a crença de que a maioria das escolhas e decisões das pessoas são as que melhor atendem seus interesses se baseia em falsa suposição.

Tal conjuntura leva a crer que não se pode abandonar de todo o caráter paternalista da atividade médica. Não é possível suprimir a participação deste profissional da decisão sobre o procedimento mais adequado ao paciente. Reconhecer que o médico é a pessoa mais capacitada para identificar as melhores opções de tratamento e de prevenção, ainda que essa maior aptidão não possa servir de subterfúgio para afastar a autonomia do paciente, é imprescindível à construção salutar da relação médico-paciente.

\section{Respeito ao poder decisório do paciente: necessidade de diálogo}

O consentimento informado e seus desdobramentos, como as diretivas antecipadas de vontade, figuram entre os instrumentos mais emblemáticos na ruptura do paradigma do paternalismo médico, servindo como mecanismo para garantir a autonomia do paciente e estimular o diálogo. A relação médico-paciente pautada pelo conhecimento científico do primeiro e pela submissão do segundo é majoritariamente considerada ultrapassada. A esse respeito, Piovesan e Dias salientam que a relação entre médico e paciente tem sofrido drásticas mudanças. O vínculo vertical, fundado no paternalismo, começou a dar lugar a um liame horizontal, baseado na autonomia do paciente ${ }^{11}$.

Ainda que a ciência médica seja tecnicamente a mais apta a eleger o tratamento mais eficaz para determinado paciente, o procedimento só será realizado após consentimento livre e esclarecido do enfermo. Há de se distinguir, portanto, o melhor tratamento segundo a ciência médica do melhor tratamento segundo a consciência do paciente. A maior eficácia não obriga o paciente a consentir, visto que nem sempre a melhor técnica e o melhor procedimento são compatíveis com seu interesse e com seus valores subjetivos.
Como muito bem expõem Beauchamp e Childress ${ }^{12}$, o respeito ao consentimento, e consequentemente à autonomia do paciente, significa honrar sua vontade, e não a presumir de acordo com premissas e subjetividade de um terceiro. O consentimento deve se referir a uma escolha atual individual, não à presunção sobre a escolha que o indivíduo poderia ou deveria fazer ${ }^{13}$.

Esclarece-se que o rompimento da relação médico-paciente estritamente paternalista se encontra no âmbito do respeito às decisões livres, autônomas e racionais do enfermo. Tal observância ao consentimento não se estende, contudo, àqueles que, em virtude de uma doença, em especial aquelas de caráter terminal, encontram-se inaptos a tomar individualmente as melhores decisões por exemplo, quando o paciente apresenta quadro depressivo. Em casos de depressão, conforme apontam Putz e Steldinger ${ }^{14}$, o desejo de recusar tratamento ou a vontade de morrer, mesmo que expressa, não devem ter respaldo médico, uma vez que a doença se caracteriza exatamente pela falta de racionalidade do paciente, retirando-Ihe a autonomia na escolha.

Não se deve, portanto, elidir tratamento de urgência com base no fato de o paciente apresentar incapacidade de racionalizar no momento decisório, ainda que tal conduta não possa ser estendida a pacientes com plenas condições cognitivas. A vontade do paciente deve ser, primeiramente, confrontada com suas verdadeiras aptidões cognitivas no momento da escolha, para que, quando comprovadamente racional e autônoma, esta seja respeitada.

Putz e Steldinger ${ }^{14}$ acreditam que o médico se encontra permanentemente vinculado à vontade do paciente, concordando ou não com ela. Para os referidos juristas, o desrespeito ao Patientenverfügung (diretivas antecipadas) viola diretamente a dignidade do enfermo, mesmo que com a intenção de o salvar. O filósofo e bioeticista americano Dan Brock, por sua vez, esclarece que na relação médico-paciente cada um traz para o processo de decisão uma informação que falta ao outro, e a comunicação é necessária para a tomada de decisão que melhor serve ao bem-estar do paciente ${ }^{15}$.

A alegação de que imputar a decisão exclusivamente ao paciente força-o a obter absoluto conhecimento de todas as informações relacionadas ao tratamento, pois só assim teria condições 
de decidir de modo consciente e refletido, induz à conclusão de que a renúncia ao direito de escolha e à própria autonomia seria a resposta mais adequada. Isso porque a maioria das pessoas não tem qualquer conhecimento científico e técnico em relação a tratamentos médicos, e se o tem é muito escasso, de modo que o mais lógico seria deixar a escolha do procedimento a cargo de profissional apto e preparado especificamente para tanto.

Mesmo que algumas das premissas de tal afirmação sejam verdadeiras, elas não são suficientes para afastar o poder decisório do paciente. O próprio exercício da autonomia observa tais constatações. A faculdade de eleger ou não determinado tratamento também passa pela decisão de ter acesso a todas as informações necessárias para tal escolha, que devem ser fornecidas pelo médico se for essa a opção do paciente. Inclusive, é lícito ao enfermo delegar a tomada de decisão para o médico, confiando-lhe toda e qualquer ação. Como bem apontam Beauchamp e Childress ${ }^{12}$, é o exercício da autonomia que legitima a delegação da escolha para médico de confiança.

Desta feita, excluir o paciente da tomada de decisão fere sua dignidade, uma vez que seus interesses pessoais são ignorados. Nesta lógica, o paciente, dotado de razão e capacidade de autodeterminação, passa a ser tratado - parafraseando as formulações do imperativo categórico de Kant ${ }^{16}$ - apenas como meio, mero instrumento da ação de um terceiro.

Percebe-se, assim, o crescente respeito à autonomia do paciente nas relações com profissionais da área médica. Tal reconhecimento, inclusive, tem sido alvo de manifestações e de diretrizes do CFM que, diante de completo vácuo legislativo, passou a regulamentar os direitos dos enfermos.

\section{Consentimento informado à luz das normativas do CFM}

Seguindo a evolução das legislações médicas como a alemã, que desde 2005 prevê a possibilidade de recusa a tratamento ${ }^{17}$-, o CFM instituiu em 9 de novembro de 2006 a Resolução $1.805^{4}$, sobre ortotanásia. Em setembro de 2009, estabeleceu ainda um código de ética médica ${ }^{18}$ amplamente marcado pelo reforço e defesa da autonomia do paciente, construção mantida pelo novo $\mathrm{CEM}^{3}$, instituído em 2018 e posteriormente modificado pelas Resoluções CFM 2.222/2018 ${ }^{19}$ e 2.226/2019 ${ }^{20}$. É digna de nota, ademais, a Resolução CFM $1.995 / 2012^{5}$, que versa sobre as diretivas antecipadas de vontade do paciente.

Logo no Capítulo I do CEM de $2018^{3}$, o texto reforça a autonomia do paciente, conferindo-lhe, na esteira da inversão da lógica paternalista, a possibilidade de escolher procedimentos e tratamentos, sujeitando o médico à sua vontade, desde que as decisões sejam adequadas ao caso e tenham respaldo científico. Imbricados na lógica de autonomia e de liberdade do enfermo, os médicos devem estar atentos à vontade do paciente, sabendo que o consentimento é o principal elo dessa relação. Tal ferramenta é desdobramento direto dos deveres de informação e de aconselhamento previstos no CEM de $2018^{3}$, que advinham já do CEM de $2009^{18}$.

Como ressaltam Dadalto e Savoi, vê-se na contemporaneidade o surgimento de modelos de relacionamento do tipo informativo $e$ interpretativo. No primeiro, o médico atua como técnico experto no assunto; é responsável por apresentar ao paciente os dados referentes a sua doença; explicam-se os fatos e fornecem-se os números, cabendo ao paciente a decisão ${ }^{21}$. Ou seja, cabe ao profissional prestar todas as informações necessárias e pertinentes ao paciente (desde que tal conduta não gere dano ao enfermo) no que toca a seu diagnóstico e a eventuais tratamentos ou procedimentos. Ademais, o médico deve aconselhar o paciente, indicando qual tratamento é, segundo a literatura e a ciência médica em geral, o mais eficaz para aquele caso, porém sem qualquer tipo de coação. Entende-se, portanto, que a saudável relação médico-paciente se pauta em princípios da bioética, cuja adequada compreensão, como apontam Azevedo e Ligiera ${ }^{22}$, lança luz sobre a questão da legitimidade ética de recusa a determinados tratamentos e terapias.

Da leitura do caput do artigo 41 do $\mathrm{CEM}^{3}$ depreende-se que o respeito à autonomia não é absoluto, uma vez que é vedado ao médico a prática da eutanásia ativa, ainda que se trate de decisão autônoma do paciente ou de seu representante legal. Porém, o parágrafo único deste mesmo artigo abre margem à ortotanásia, desde que se trate de doença incurável e terminal e que a vontade do paciente ou de seu representante 
legal esteja manifestamente expressa no sentido de recusar ações terapêuticas obstinadas, limitando-se o tratamento a cuidados paliativos ${ }^{3}$.

Para interpretar de modo mais completo o aludido artigo, é pertinente apontar sua conformação com as Resoluções CFM 1.995/2012 ${ }^{5}$ e $2.232 / 2019^{6}$, que visam regulamentar as diretivas antecipadas de vontade e a recusa terapêutica. Esses diplomas preveem a possibilidade de pacientes terminais recusarem determinados tratamentos, limitando-se a assistência a cuidados paliativos. Esse raciocínio também é defendido por Fernandes e Goldim, os quais apontam que $o$ sistema brasileiro já sinaliza a construção de um modelo normativo em prol da autodeterminação dos pacientes na situação de final de vida e de terminalidade, acompanhada de consultoria e atendimento médico devido ${ }^{23}$.

Porém, é importante distinguir a ortotanásia (tratamentos paliativos) da eutanásia passiva. A recusa de tratamentos em casos de morte iminente sem que haja doença terminal ou incurável segue sem respaldo normativo. Conforme exposto anteriormente, a possibilidade de declinar tratamento encontra-se limitada aos casos de doenças terminais, no sentido de evitar a obstinação irrazoável.

Da análise das regulações brasileiras, parece seguro afirmar, até o momento, que a autonomia do paciente deve ser respeitada, principalmente em casos terminais. Não obstante, identificam-se alguns limites a essa autonomia, ainda que não se encontrem suficientemente claros. Outrossim, é importante asseverar que as normativas do CFM não ecoam na legislação atual, havendo lacuna jurídica no que toca à ortotanásia e ao próprio respeito à autonomia do paciente.

De qualquer modo, o respeito à autonomia é também o respeito à liberdade e, consequentemente, à responsabilidade na tomada de decisão individual. Como aponta Brock ${ }^{24}$, deve coexistir na autonomia o correlato sentimento de responsabilidade, de modo que os indivíduos não possam se eximir das consequências de suas decisões autônomas.

Destarte, defende-se que não se pode responsabilizar o médico pela decisão livre e esclarecida do paciente, mesmo que a consequência de tal decisão seja a morte. Assim, o médico se exime da responsabilidade sobre a escolha feita pelo paciente, sendo responsável apenas pela informação prestada, pela forma como foi direcionada ao paciente e pela técnica empregada na execução da conduta selecionada.

\section{Arquiteto da escolha: conformação da autonomia ao paternalismo médico}

A análise das normativas atinentes à relação médico-paciente e à própria construção teórica sobre a necessidade de respeitar a autonomia do enfermo evidencia impasse na atividade médica. Como uma profissão marcada desde seu início por caráter eminentemente paternalista pode se adequar a essa demanda? Neste cenário, propõe-se implementar o que Thaler e Sunstein ${ }^{1}$ denominaram "paternalismo libertário".

Em Nudge ${ }^{1}$, os autores desenvolveram o conceito de "arquiteto da escolha", o qual, por seu maior conhecimento técnico e científico, é o responsável por ambientar o outro em sua especialidade. $\mathrm{O}$ arquiteto da escolha deve não só fornecer todas as informações necessárias à pessoa que não pertence ao seu campo do saber, mas também aconselhá-la e instigá-la a tomar a melhor decisão segundo parâmetros técnicos e científicos.

Cabe apontar, no entanto, que esse aconselhamento e incentivo não podem constranger a pessoa que busca a assistência do expert. Em nenhum momento Thaler e Sunstein ${ }^{1}$ defendem que o arquiteto da escolha imponha suas ideias, apenas que apresente todas as possibilidades. É facultado a ele expressar sua opinião, inclusive indicando determinado comportamento como o de sua preferência, porém nunca de forma a coagir o outro ${ }^{1}$. Assim, tem-se o paternalismo na indução a determinada conduta, mas a liberdade de escolha é individual - por isso a formulação do termo "paternalismo libertário".

Trazendo tal formulação ao contexto médico-hospitalar, o paternalismo libertário se articula a partir da figura do profissional médico - afinal, como detentor do conhecimento técnico e científico, a ele cabe o papel de "arquiteto da escolha". Compete ao médico familiarizar o paciente com seu próprio quadro, transmitindo todas as informações pertinentes e necessárias à adequada compreensão do diagnóstico, dos possíveis tratamentos e procedimentos e das consequências da não intervenção. Inclusive, o profissional deve indicar 
- a partir da exposição dos riscos, das chances de sucesso e da efetividade de cada tratamento - a opção mais eficaz segundo parâmetros técnicos e científicos, confiando a escolha, contudo, ao paciente.

Se observado com atenção, o próprio CEM prevê conduta em conformidade com esta noção de paternalismo libertário. Seu Capítulo II dispõe que é direito do médico (...) indicar o procedimento adequado ao paciente, observadas as práticas cientificamente reconhecidas e respeitada a legislação vigente ${ }^{25}$. Da mesma forma, no Capítulo IV o artigo 24 veda ao médico deixar de garantir ao paciente o exercício do direito de decidir livremente sobre sua pessoa ou seu bem-estar, bem como exercer sua autoridade para limitá- $\mathrm{IO}^{26}$. Esse item deve ser lido em conjunto com o artigo 34, que obriga o médico a informar ao paciente o diagnóstico, o prognóstico, os riscos e os objetivos do tratamento, salvo quando a comunicação direta possa lhe provocar dano ${ }^{27}$, e com o artigo 13, que impede o médico de deixar de esclarecer o paciente sobre as determinantes sociais, ambientais ou profissionais de sua doença ${ }^{28}$. Também nesse sentido, o artigo 22 exige que o médico obtenha o consentimento do paciente ou de seu representante legal ${ }^{29}$, prevendo a figura do consentimento informado, ferramenta essencial ao respeito da autonomia do paciente, conforme já explicitado.

\section{Não maleficência e beneficência: parâmetros do paternalismo libertário}

Antes de analisar casos concretos, é importante tecer algumas considerações sobre os princípios de beneficência médica e não maleficência, os quais, além de estabelecerem limites à autonomia do paciente e do próprio médico, prestam-se a nortear a implementação de um paternalismo libertário. Em que pese sua grande proximidade, a aplicação prática desses dois princípios pode se demonstrar quase antagônica. Enquanto a beneficência se vincula à lógica do melhor tratamento para o paciente, com respeito à sua autonomia e busca de alternativas mais apropriadas de tratamento, o princípio da não maleficência é óbice a posturas irrazoáveis do médico, mesmo quando este pretende realizar o melhor para o paciente.
Nem sempre é fácil distinguir procedimentos benéficos de procedimentos infrutíferos. Consoante Dadalto e Savoi, a morte tem se tornado um evento postergável, em que o limite para a intervenção médica muitas vezes é elástico e imponderável ${ }^{30}$. A busca incondicional por restabelecer a saúde ou manter artificialmente a vida do paciente pode ocorrer de diversas formas, desde tratamentos inúteis, meramente paliativos, até a manutenção de um estágio de coma irreversível, caracterizando a chamada "distanásia" ou "obstinação irrazoável".

Segundo Gawande ${ }^{31}$, o éthos médico contrário à morte, aliado ao desejo de imortalidade, criou verdadeiro problema nos dois polos da relação hospitalar, pois médicos, pacientes e familiares buscam, por vezes de modo irracional, lutar por uma vida irrecuperável. O problema da obstinação irrazoável, portanto, não se resume exclusivamente a condutas médicas, mas também à própria autonomia do paciente, que não pode justificar tratamentos comprovadamente inúteis. Nesse sentido, o princípio da não maleficência, em conjunto com a proibição da obstinação irrazoável, limita tanto a conduta médica quanto a autonomia do paciente, buscando solução mais próxima do respeito à dignidade e evitando formas desnecessárias de sofrimento.

Em contexto no qual tanto a postura médica quanto a autonomia do paciente (por vezes em conjunto) podem suscitar procedimentos infrutuosos, é preciso promover o diálogo entre as partes, de modo a estabelecer limites. Enquanto de um lado se impõem ao médico barreiras técnicas, de outro figuram ao paciente limitações de acordo com convicções de ordem religiosa ou filosófica, que podem, inclusive, ser registradas em testamento vital.

O diálogo é importante porque o próprio conceito de distanásia é flexível, uma vez que tratamentos inaceitáveis para um paciente podem ser considerados absolutamente plausíveis por outro. Caso o paciente deixe claro ser contra determinados procedimentos, preferindo receber apenas tratamentos paliativos, parece não haver qualquer possibilidade de distanásia. Porém, como proceder quando o paciente registra em seu testamento vital que deseja ser submetido a procedimentos típicos de obstinação terapêutica irrazoável? Deve o médico respeitar esse testamento, visto 
que redigido de modo autônomo e consciente, portanto com todos os pressupostos de validade?

Como defendem Dadalto e Savoi, práticas de distanásia limitam a autonomia do paciente porque ferem premissa básica da arte médica: primum non nocere (em primeiro lugar, não causar o mal) ${ }^{32}$. As autoras salientam ainda que $a$ contrariedade do testamento vital em relação às normas éticas-disciplinares configura verdadeira limitação ao conteúdo do testamento vital e, portanto, essa disposição deve ser interpretada como não escrita ${ }^{32}$.

Segundo o artigo 41, parágrafo único, do CEM, nos casos de doença incurável e terminal, deve o médico oferecer todos os cuidados paliativos disponiveis sem empreender ações diagnósticas ou terapêuticas inúteis ou obstinadas, levando sempre em consideração a vontade expressa do paciente ou, na sua impossibilidade, a de seu representante legal ${ }^{33}$. Tratando-se de paciente capaz, parece simples resolver o problema. Basta que exista diálogo entre as partes e que o médico esclareça quais são as possibilidades de tratamento e suas consequências e quais são as medidas inúteis.

Tecidas tais considerações, passa-se à análise de hard cases a partir da ideia de paternalismo libertário.

\section{Testemunhas de Jeová}

Um dos casos mais debatidos em termos de bioética e autonomia do paciente é o das testemunhas de Jeová. Pacientes da referida religião recusam, em virtude de suas crenças e dogmas, qualquer tipo de tratamento que envolva transfusão de sangue. Diante de tal impasse, questiona-se: seria legítima a recusa de tratamento mesmo nos casos em que ela resultaria invariavelmente no óbito do paciente? E ainda: qual é o alcance do termo "iminente risco de morte"?

Em que pese o $\mathrm{CEM}^{3}$ possibilitar ao médico negar a recusa de tratamento em casos de iminente risco de morte (artigo 31), o Judiciário, ainda que não de forma pacífica, já reconheceu a legitimidade da solicitação do paciente. No julgamento do Agravo de Instrumento 70032799041, o Tribunal de Justiça do Estado do Rio Grande do Sul (TJRS) entendeu que deve prevalecer a liberdade de crença e a opção por tratamento que preserve a dignidade do paciente:
Agravo de Instrumento. Direito privado não especificado. Testemunha de Jeová. Transfusão de sangue. Direitos fundamentais. Liberdade de crença e dignidade da pessoa humana. Prevalência. Opção por tratamento médico que preserva a dignidade da recorrente. A decisão recorrida deferiu a realização de transfusão sanguínea contra a vontade expressa da agravante, a fim de preservar-lhe a vida. A postulante é pessoa capaz, está lúcida e desde o primeiro momento em que buscou atendimento médico dispôs, expressamente, a respeito de sua discordância com tratamentos que violem suas convicções religiosas, especialmente a transfusão de sangue. Impossibilidade de ser a recorrente submetida a tratamento médico com o qual não concorda e que para ser procedido necessita do uso de força policial. Tratamento médico que, embora pretenda a preservação da vida, dela retira a dignidade proveniente da crença religiosa, podendo tornar a existência restante sem sentido. Livre arbítrio. Inexistência do direito estatal de "salvar a pessoa dela própria", quando sua escolha não implica violação de direitos sociais ou de terceiros. Proteção do direito de escolha, direito calcado na preservação da dignidade, para que a agravante somente seja submetida a tratamento médico compatível com suas crenças religiosas. Agravo provido ${ }^{34}$.

O tema segue sendo alvo de pareces e resoluções do CFM e de discussões jurídicas, ainda distante de consenso. Cita-se, inicialmente, o Parecer CFM $12 / 2014^{35}$, no qual o Conselho responde a questionamentos da Associação das Testemunhas de Jeová quanto à recusa a tratamentos que envolvam transfusão de sangue, mormente em relação aos preceitos da Resolução CFM 1.021/1980 ${ }^{36}$. O conselheiro-relator esclareceu, à época, que nenhuma pessoa adulta e apta a decidir pode ser obrigada a receber tratamento contrário à sua vontade, e que não há clareza quanto ao termo "iminente risco de morte". Desse modo, argumenta que urge a publicação de uma nova Resolução e consequente revogação da Resolução CFM $n^{\circ} 1.021 / 80$, após a elaboração de precisas, claras e objetivas diretrizes técnicas, em um prazo máximo de seis meses, determinantes dos limites e parâmetros da indicação para a transfusão de sangue e seus componentes ${ }^{37}$.

Em 2018, um ano antes de a Resolução CFM $1.021 / 1980^{36}$ ser revogada, o Conselho Regional 
de Medicina de Minas Gerais, provocado a editar parecer (103/2018) sobre o alcance do termo "situações iminentes de risco à vida", reiterou o seguinte entendimento: Como estabelecido na resolução vigente [Resolução CFM 1.021/1980], nas situações de risco iminente de morte vale o preceito de se manter a vida. Entretanto, esta decisão não se encontra totalmente pacificada. A legislação, em especial a CR88 [Constituição de 1988] privilegia o direito à vida, entretanto a jurisprudência, em alguns aspectos, considera a dignidade tão ou mais importante que a vida. Não há consenso sobre o tema, mas do ponto de vista ético, a resolução vigente permite a transfusão ${ }^{38}$.

Em 2019, cinco anos após o Parecer CFM $12 / 2014^{35}$, a Resolução CFM 1.021/1980 ${ }^{36}$ foi finalmente revogada pela Resolução CFM 2.232/2019 ${ }^{6}$. Porém, o artigo $3^{\circ}$ da nova resolução manteve o exato entendimento quanto à conduta a ser adotada pelo médico em casos de risco iminente de morte. Ou seja, em situações-limite, a transfusão pode ser feita mesmo contra a vontade do paciente ${ }^{6}$.

No mesmo ano, em razão da dificuldade de se estabelecer critérios quanto à primazia do direito à vida ou à autodeterminação (estando esse vinculado à dignidade da pessoa humana), o Ministério Público Federal (MPF) apresentou a Arguição de Descumprimento de Preceito Fundamental $618^{39}$. A referida demanda, entre outros pontos, questiona o alcance da Resolução CFM 1.021/1980, solicitando a retirada do item 2 do Parecer Processual CFM 21/1980, adotado como anexo daquela Resolução, que prescreve: Se houver iminente perigo de vida, o médico praticará a transfusão de sangue, independentemente de consentimento do paciente ou de seus responsáveis ${ }^{36}$. A fundamentação do MPF faz clara referência à autonomia da vontade, entendendo que, ao se preservar o poder decisório do paciente, mesmo em casos-limite, respeita-se a sua dignidade, que poderá prevalecer inclusive quando em conflito com o direito à vida.

Sob o ponto de vista do paternalismo libertário, a recusa do tratamento, com fulcro no argumento de que este violaria a dignidade do paciente, também seria lícita, sendo o paciente responsável por tal decisão. O médico, por seu turno, poderia desaconselhar tal conduta apontando consequências físicas e técnicas, porém não teria o direito de impor tratamento ou procedimento não consentido.
Tal conclusão, contudo, não impede que o médico se recuse a atender o paciente, encaminhando-o a outro profissional. Considerando os direitos fundamentais, que também protegem os médicos e toda a equipe hospitalar, Putz e Steldinger ${ }^{14}$ apontam que a liberdade de consciência dos profissionais deve ser igualmente respeitada, desde que não se trate de caso de morte iminente e que o paciente consiga encontrar outro profissional apto a tratá-lo. Na mesma linha dispõe o inciso VII do Capítulo I do CEM: O médico exercerá sua profissão com autonomia, não sendo obrigado a prestar serviços que contrariem os ditames de sua consciência ou a quem não deseje, excetuadas as situações de ausência de outro médico, em caso de urgência ou emergência, ou quando sua recusa possa trazer danos à saúde do paciente ${ }^{40}$.

Tal situação, inclusive, foi objeto apreciado pelo TJRS na Apelação Cível $70071994727^{41}$, em que se discutiu o conflito entre liberdade profissional do médico e liberdade religiosa do paciente, ficando assegurado o direito de recusa do profissional. No caso, um paciente, Testemunha de Jeová, com indicação de procedimento cirúrgico de ressecção transuretral da próstata, recusou tratamento de transfusão de sangue, caso fosse necessário, em razão de crenças religiosas. Diante disso, o médico anestesista, por razões de consciência e com base no $\mathrm{CEM}^{3}$, negou-se a participar da cirurgia.

Modificando a sentença condenatória, o TJRS ${ }^{41}$ deu provimento à apelação interposta julgando improcedente o pedido indenizatório. O tribunal entendeu que, diante da ausência de risco de morte iminente e da possibilidade de encaminhamento a outro profissional moral e ideologicamente desimpedido, a conduta do médico foi lícita, a exemplo de posicionamento já adotado pelo Supremo Tribunal Federal quando do julgamento do Agravo Interno no Recurso Extraordinário com Agravo $988796^{42}$.

\section{Considerações finais}

Em cenário de rápida evolução científica, constante promoção da autonomia e necessário conhecimento técnico por parte do médico, o paternalismo libertário apresenta-se como opção viável para manter certo grau de paternalismo sem renunciar ao autogoverno e ao direito de escolha do paciente. Apesar das limitações do paciente na 
tomada de decisão, especialmente no que toca à falta de conhecimento técnico e científico, não se pode suprimir sua autonomia, dando margem a situações de violação da dignidade.

Cabe ao médico, portanto, o papel de arquiteto da escolha, capaz de dar novo sentido ao dever de informar. O profissional, assim, passa a ter outra postura ao transmitir informações ao paciente, seja no diagnóstico ou nas diferentes etapas do tratamento. Como afirmado, o médico deve não só fornecer todas as informações necessárias e pertinentes ao paciente, mas aconselhá-lo e, inclusive, indicar o tratamento mais adequado segundo parâmetros técnicos e científicos, arquitetando, segundo a melhor prática, o modo como essas informações são prestadas.

Dessa forma, o paciente será induzido ou instigado (nudged) a determinado comportamento, porém sem que tal encorajamento se torne coação ou imposição. Assim, o enfermo estará apto a tomar a melhor decisão, levando em conta não só aspectos técnicos, mas subjetivos e pessoais, tendo respeitada sua autonomia e, em ultima ratio, sua dignidade.

\section{Referências}

1. Thaler RH, Sunstein CR. Nudge: improving decisions about health, wealth and happiness. London: Penguin; 2009.

2. Thaler RH, Sunstein CR. Op. cit. p. 3. Tradução livre.

3. Conselho Federal de Medicina. Código de Ética Médica: Resolução CFM $n^{\circ} 2.217$, de 27 de setembro de 2018, modificada pelas Resoluções CFM n 2.222/2018 e 2.226/2019 [Internet]. Brasília: Conselho Federal de Medicina; 2019 [acesso 25 fev 2021]. Disponível: https://bit.ly/3cvLk8R

4. Conselho Federal de Medicina. Resolução CFM $n^{\circ} 1.805$, de 9 de novembro 2006. Na fase terminal de enfermidades graves e incuráveis, é permitido ao médico limitar ou suspender procedimentos e tratamentos que prolonguem a vida do doente, garantindo-lhe os cuidados necessários para aliviar os sintomas que levam ao sofrimento, na perspectiva de uma assistência integral, respeitada a vontade do paciente ou seu representante legal. Diário Oficial da União [Internet]. Brasília, p. 169, 28 nov 2006 [acesso 20 out 2019]. Seção 1. Disponível: https://bit.ly/3pJADTF

5. Conselho Federal de Medicina. Resolução CFM n 1.995, de 9 de agosto de 2012. Dispõe sobre as diretivas antecipadas de vontade dos pacientes. Diário Oficial da União [Internet]. Brasília, p. 269-70, 31 ago 2012 [acesso 20 out 2019]. Seção 1. Disponível: https://bit.ly/3cAnokl

6. Conselho Federal de Medicina. Resolução CFM n².232, de 17 de julho de 2019. Estabelece normas éticas para a recusa terapêutica por pacientes e objeção de consciência na relação médico-paciente. Diário Oficial da União [Internet]. Brasília, p. 113-4, 16 set 2019 [acesso 3 nov 2019]. Seção 1. Disponível: https://bit.ly/3ar9T46

7. Kraut JA. Los derechos de los pacientes. Buenos Aires: Abeledo-Perrot; 1997.

8. Associação Médica Mundial. Declaração de Helsinki V [Internet]. 1997 [acesso 11 mar 2019]. Disponível: https://bit.ly/2YCBw4H

9. Sarlet IW, Molinaro CA. Democracia: separação de poderes: eficácia e efetividade do direito à saúde no Judiciário brasileiro: Observatório do Direito à Saúde. Belo Horizonte: Faculdade de Filosofia e Ciências Humanas; 2011.

10. Organização Mundial da Saúde. Constituição da Organização Mundial da Saúde (OMS/WHO) de 1946 [Internet]. São Paulo: Biblioteca Virtual de Direitos Humanos; 2006 [acesso 30 mar 2019]. Disponível: https://bit.ly/2YCHRNv

11. Piovesan F, Dias R. Proteção jurídica da pessoa humana e o direito à morte digna. In: Godinho AM, Leite GS, Dadalto L, coordenadores. Tratado brasileiro sobre o direito fundamental à morte digna. São Paulo: Almedina; 2017. p. 55-77. p. 73.

12. Beauchamp TL, Childress JF. Principles of biomedical ethics. $5^{\text {a }}$ ed. New York: Oxford University Press; 2001. 
13. Beauchamp TL, Childress JF. Op. cit. p. 66. Tradução livre.

14. Putz W, Steldinger B. Patientenrechte am Ende des Lebens: Vorsorgevollmacht, Patientenverfügung, Selbstbestimmtes Sterben. München: DTV; 2016.

15. Brock DW. Life and death: philosophical essays in biomedical ethics. New York: Cambridge University Press; 1993. p. 150. Tradução livre.

16. Kant I. Fundamentação da metafísica dos costumes. Lisboa: Edições 70; 1986.

17. Prediel C. Sterbehilfepolitik in Deutschland: Eine Einführung. Wiesbaden: Springer; 2015.

18. Conselho Federal de Medicina. Resolução CFM n 1.931, de 17 de setembro de 2009. Aprova o Código de Ética Médica. Diário Oficial da União [Internet]. Brasília, p. 90, 24 set 2009 [acesso 2 jun 2019]. Seção 1. Disponível: https://bit.ly/3rgYquA

19. Conselho Federal de Medicina. Resolução $\mathrm{CFM} \mathrm{n}^{\circ} 2.222$, de 23 de novembro de 2018. Corrige erro material do Código de Ética Médica (Resolução CFM n ${ }^{\circ} 2.217 / 2018$ ) publicado no D.O.U. de $1^{\circ}$ de novembro de 2018, Seção I, p. 179. Diário Oficial da União [Internet]. Brasília, 11 dez 2018 [acesso 2 jun 2019]. Seção 1. Disponível: https://bit.ly/3r9M9bk

20. Conselho Federal de Medicina. Resolução CFM n 2.226, de 21 de março de 2019. Revoga a Resolução CFM $\mathrm{n}^{\circ} 1.649 / 2002$, os artigos $4^{\circ}$ e $5^{\circ}$ e seu parágrafo único da Resolução CFM $n^{\circ} 2.170 / 2017$ e altera o artigo 72 do Código de Ética Médica, que proíbem descontos em honorários médicos através de cartões de descontos e a divulgação de preços das consultas médicas de forma exclusivamente interna. Diário Oficial da União [Internet]. Brasília, p. 185, 5 abr 2019 [acesso 2 jun 2019]. Seção 1. Disponível: https://bit.ly/2YCJOJJ

21. Dadalto L, Savoi C. Distanásia: entre o real e o irreal. In: Godinho AM, Leite GS, Dadalto L, coordenadores. Tratado brasileiro sobre direito à morte digna. São Paulo: Almedina; 2017. p. 151-64. p. 154.

22. Azevedo AV, Ligiera WR, coordenadores. Direitos do paciente. São Paulo: Saraiva; 2012.

23. Fernandes MS, Goldim JR. Atividade médica em situações de final de vida e terminalidade: uma reflexão jurídica e bioética. In: Paschoal JC, Silveira MJ, coordenadores. Livro homenagem a Miguel Reale Júnior. São Paulo: GZ; 2014. p. 397-412. p. 399.

24. Brock DW. Op. cit.

25. Conselho Federal de Medicina. Código de Ética Médica: Resolução CFM n 2.217. Op. cit. p. 19.

26. Conselho Federal de Medicina. Código de Ética Médica: Resolução CFM n² 2.217. Op. cit. p. 25.

27. Conselho Federal de Medicina. Código de Ética Médica: Resolução CFM n 2.217. Op. cit. p. 27.

28. Conselho Federal de Medicina. Código de Ética Médica: Resolução CFM n 2.217. Op. cit. p. 22.

29. Conselho Federal de Medicina. Código de Ética Médica: Resolução CFM n² 2.217. Op. cit. p. 25.

30. Dadalto L, Savoi C. Op. cit. p. 154.

31. Gawande A. Mortais: nós, a medicina e o que realmente importa no final. Rio de Janeiro: Objetiva; 2015.

32. Dadalto L, Savoi C. Op. cit. p. 157.

33. Conselho Federal de Medicina. Código de Ética Médica: Resolução CFM n 2.217. Op. cit. p. 28.

34. Rio Grande do Sul. Tribunal de Justiça. Agravo de Instrumento n 70032799041 . Décima Segunda Câmara Cível. Direito privado não especificado. Testemunha de Jeová. Transfusão de sangue. Agravante: Heliny Cristina Lucas Alho. Agravado: Fundação Universidade de Caxias do Sul. Relator: Cláudio Baldino Maciel. Poder Judiciário do Estado do Rio Grande do Sul [Internet]. 2010 [acesso 25 out 2019]. Disponível: https://bit.ly/3cGhLkT

35. Conselho Federal de Medicina. Parecer CFM $n^{\circ}$ 12, de 26 de setembro de 2014. Estabelece a necessidade da publicação de resolução sobre transfusão de sangue e a revogação da Resolução CFM $\mathrm{n}^{\circ}$ 1.021/1980, após a elaboração de diretrizes técnicas pelas Sociedades Médicas de Especialidades com apoio de jurisconsultos, em um prazo máximo de seis meses, determinantes dos limites e parâmetros da sua indicação e de seus componentes. CFM [Internet]. 26 set 2014 [acesso 10 dez 2020]. Disponível: https://bit.ly/3pEUOIP 
36. Conselho Federal de Medicina. Resolução $n^{\circ} 1.021$, de 26 de setembro de 1980. Adota os fundamentos do parecer anexo como interpretação autêntica dos dispositivos deontológicos referentes a recusa em permitir a transfusão de sangue, em casos de iminente perigo de vida. Diário Oficial da União [Internet]. Brasília, p. 75, 22 out 1980 [acesso 3 fev 2021]. Seção 1. Disponível: https://bit.ly/36Dc5nP

37. Conselho Federal de Medicina. Op. cit. 2014. p. 6.

38. Conselho Regional de Medicina de Minas Gerais. Parecer CRM-MG n 103, de 15 de junho de 2018. A transfusão sanguínea em situações iminentes de risco à vida está autorizada na Resolução CFM n 1.021/1980. CRM-MG [Internet]. 2018 [acesso 10 dez 2020]. p. 7. Disponível: https://bit.ly/3jahzlC

39. Brasil. Supremo Tribunal Federal. Arguição de Descumprimento de Preceito Fundamental $n^{\circ} 618$. Relator: Min. Nunes Marques. STF [Internet]. 2019 [acesso 15 jan 2019]. Disponível: https://bit.ly/36GtvAe

40. Conselho Federal de Medicina. Código de Ética Médica: Resolução CFM n 2.217. Op. cit. p. 15.

41. Rio Grande do Sul. Tribunal de Justiça. Apelação Cível $n^{\circ} 70071994727$. Décima Câmara Cível. Procedimento cirúrgico. Negativa do médico em prestar seus serviços. Apelante: Hospital Irmandade Santa Casa de Misericórdia de Porto Alegre. Apelado: Janoni Coraldino da Silva Rolim. Relator: Túlio de Oliveira Martins. Poder Judiciário do Estado do Rio Grande do Sul [Internet]. 2017 [acesso 25 out 2019]. Disponível: https://cutt.ly/Mkf5dT1

42. Brasil. Supremo Tribunal Federal. Agravo Interno no Recurso Extraordinário com Agravo ${ }^{\circ} 988796$. Consumidor. Plano de saúde. Cirurgia bariátrica. Recusa a transfusão de sangue. Cancelamento da cirurgia. Agravante: Alex Vieira dos Santos. Agravado: Amil Assistência Médica Internacional S.A. Relator: Min. Luiz Fux. STF [Internet]. 2017 [acesso 25 out 2019]. Disponível: https://bit.ly/3rc9k40

Andrei Ferreira de Araújo Lima - Doutorando - andrei@araujolimaemachado.com.br

(D) 0000-0002-3153-9688

Fernando Inglez de Souza Machado - Mestre - fernando@araujolimaemachado.com.br

(D) $0000-0002-7629-6552$

Correspondência

Andrei Ferreira de Araújo Lima - Rua Dom Pedro II, 817, Higienópolis

CEP 90550-142. Porto Alegre/RS, Brasil.

Participação dos autores

Andrei Ferreira de Araújo Lima foi responsável pela formulação inicial dos tópicos sobre testemunha de Jeová, não maleficência e beneficência, arquiteto da escolha e respeito ao poder decisório. Fernando Inglez de Souza Machado foi responsável pela formulação inicial da introdução, das considerações finais e dos tópicos do consentimento informado e paternalismo versus autonomia.

Recebido: 24.11.2019

Revisado: $\quad 5.1 .2021$

Aprovado: $\quad 7.1 .2021$ 